\title{
Significantly high levels of estrogen and MDA together induce tumor progression in Oral squamous cell carcinoma
}

\author{
A.Nath ${ }^{1}$, Vishal Anand ${ }^{5}$, Aseem Kumar Anshu ${ }^{1}$, Tuhin Rashmi ${ }^{6}$, J.K Singh ${ }^{4}$, \\ Preety Jain ${ }^{2}$, Reena Sinha ${ }^{3}$ and Shailendra Kumar ${ }^{1}$ \\ ${ }^{1}$ Research Centre, Mahavir Cancer Institute and Research Centre, Phulwarisharif, Patna \\ ${ }^{2}$ Department of Surgery, Mahavir Cancer Institute and Research Centre, Phulwarisharif, Patna \\ ${ }^{3}$ Department of Pathology, Mahavir Cancer Institute and Research Centre, Phulwarisharif, Patna \\ ${ }^{4}$ Dept. of Radiation Oncology, Mahavir Cancer Institute and Research Centre, Phulwarisharif, Patna \\ ${ }^{5}$ Department of Bio-engineering, BIT, Mesra, Ranchi \\ ${ }^{6}$ Amity Institute of Biotechnology, Amity University, Noida, U.P
}

\begin{abstract}
Oral squamous cell carcinoma (OSCC) is believed to possess one of the highest incidences every year in India. A definitive link between tobacco consumption and development of Oral cancer has been repeatedly reported in several studies in the past. Tobacco has been associated with cancer progression in patients of OSCC by the generation of Reactive Oxygen Species (ROS). The abundant polyunsaturated fatty acid (PUFA) in membranes upon degradation by free radicals or ROS, produces malondialdehyde (MDA). Thiobarbituric acid reactive substance (TBARS) was assessed for the presence of MDA by Lipid peroxidation assay method using the standard protocol. Hematological parameters (RBC count, Hemoglobin level, WBC count and Platelet count) were also studied. Estrogen levels were estimated using estrogen ELISA kit. Statistical analysis produced significant variations. For histopathological study, tissues collected from oral cancer patients were processed, sectioned and stained with hematoxylin and eosin. MDA levels were found to be significantly high in OSCC patients. The MDA level increased in serum of Grade I, II \& III. Upon comparison with healthy patients, the RBC count was found to be lower, whereas, the WBC count was relatively higher in oral cancer patients. Estrogen levels were higher in male OSCC patients as compared to the female patients. In conclusion, high oxidative stress and high estrogen levels in male patients have a direct linkage with OSCC. Histopathological study uncovers substantial information about cell anatomy.
\end{abstract}

Keywords: OSCC, TBARS, ROS, MDA, Estrogen

\section{Introduction}

Oral cancer is a malignant neoplasm that develops on the lip, in the mouth or the tissues of the oral cavity and the oropharynx. About two-thirds of all oral cancers occur in mouth and about one-third develops in the pharynx region. 75 percent of all oral cancers have been associated with the consumption of tobacco or alcohol or both. A combination of tobacco and alcohol is more dangerous than either alone. Tobacco is an established exogenous stimulus for reactive oxygen species which is associated with the promotion of mutagenesis and carcinogenesis and is therefore, believed to be a major etiological factor for oral, head and neck cancer. More than $90 \%$ of oral cancers have their origin in squamous cells which are flat, scale-like cells that normally form the lining of the mouth and throat. Such oral cancers are therefore, known as squamous cell carcinoma.

Free radicals such as superoxide anion $\left(\mathrm{O}_{2}^{-\mathrm{o}}\right)$, per hydroxyl radical $\left(\mathrm{HO}_{2}{ }^{\circ}\right)$, hydroxyl radical $\left({ }^{\circ} \mathrm{OH}\right)$ are produced during normal cellular metabolism and Reactive oxygen species (ROS) are generated during electron transport chain, mainly in the mitochondria [1]. ROS is believed to play a significant role in the progression of various diseases like cancer, cataract, atherosclerosis, diabetes and neurodegenaration. As damaging agent, ROS is also associated with essential processes like apoptosis, phagocytosis and building up detoxification reactions. Cells have antioxidant enzymes such as superoxide dismutase, MnSOD, CuZnSOD, catalase and hydrolase to prevent the damage from ROS [2]. Apoptosis is a particularly important process which has significant role in the elimination of pre cancerous and cancerous cells [3].

Lipid peroxidation (LPO) refers to the oxidative degradation of lipids like polyunsaturated fatty acid [4]. PUFA, containing two or more carbon-carbon double bonds, are highly reactive to peroxidation and result in the formation of lipoperoxyl radicals (LOO) which further react with lipid chains to generate lipid radicals and lipid hydroperoxides (LOOH). Byproducts of lipid peroxidation may serve as oxidative stress biomarkers due to their prolonged half life and their ability to diffuse through plasma membrane, unlike free radicals. These byproducts are mostly aldehydes like malondialdehyde, hexanal, 4-hydrooxynonenal and acrolein. Being extremely reactive these molecules have received a lot of attention [5]. This entire process of lipid peroxidation, 
their disintegration along with the formation of reactive compounds can lead to changes in the permeability and fluidity of the membrane lipid bilayer weakening cell integrity dramatically [6].

High levels of estrogen have been well documented to cause progression of different types of tumor. Biosynthesis of estrogen is catalyzed by estrogen synthase (aromatase) enzyme by the aromatization of circulating androgens like testosterone and androstenedione to form estradiol and estrone respectively. [8] Higher estrogen actually stimulates proliferation of pre-adipocytes and mature adipocytes. Estrogen emanating from adipose tissue channels fat to subcutaneous and breast tissues [7\&9]. It has been affirmed by a report that aromatase activity increases with age and body fat mass [7]. Thus, men with higher aromatase activity, tend to have a higher level of estrogen in their blood. Older men are prone to depositing fat in their abdomen, back and thigh regions a condition which induces raised production of estrogen possibly by developing hyper activated aromatase which leads to increased production of estrogen and ultimately initiates proliferation of precancerous cells in head and neck regions.

Thus this study was conducted to assess the pattern displayed by the MDA levels, estrogen levels, hematological parameters together with histopathological variations in cancerous tissue and serum of patients suffering with oral cancer.

\section{Materials and Method:}

Blood samples were taken from 120 cancer patients identified with oral cancer of grades I, II and III along with samples from 45 normal persons. The malignant cases were patients undergoing treatment at Mahavir Cancer Institute, Phulwarisharif, Patna, Bihar and the study was conducted with proper consent from them. Blood was used for reading the haemoglobin level, RBC, WBC and platelet count; while serum was used for LPO assay and estrogen level analysis. Malignant tissues were collected from the operation theatre at the institute and paraffin blocks were prepared for histopathological study.

\subsection{Lipid peroxidation evaluation:}

The MDA content was determined by (Thiobarbituric acid) TBA reaction according to standard procedure with minor modifications [10]. $2.5 \mathrm{ml}$ of $10 \%$ TCA was added to $500 \mu \mathrm{l}$ of serum (test sample) and $500 \mu \mathrm{l}$ of distilled water (control) both. Test tubes were incubated at $95^{\circ} \mathrm{c}$ for $15 \mathrm{~min}$. The test tube were cooled and then centrifuged for $10 \mathrm{~min}$ at $3000 \mathrm{rpm}$. $1 \mathrm{ml}$ of $0.675 \%$ TBA was added to $2 \mathrm{ml}$ of the supernatant in the tubes and this was followed by incubation at $90^{\circ} \mathrm{c}$ for $15 \mathrm{~min}$. The optical density of the color reaction was taken at $532 \mathrm{~nm}$ and MDA level was calculated as per the standard graph.

\subsection{Estrogen test:}

$25 \mu 1$ of serum were poured in different wells of ELISA kit, $100 \mu$ l of enzyme conjugate was added and incubated for 1hour, before washing 3 times with wash buffer. TMB substrate solution was added to each test serum and incubated for 30 minutes for reaction to take place, and then stop solution was added to stop the reaction after which the test solution gave a yellow color. Optical density was taken at 450nm and matched with standard prepared earlier.

\subsection{Haematological Parameters: -}

Haemoglobin level, RBC count, WBC count and Platelet count were estimated by standard procedures using Cell Counter (Medonic M- Series) in the Department of Haematology, Mahavir Cancer Institute, Patna.

\subsection{Histopathological procedure -}

Tissue histology was studied by collecting tissues of oral cancer patients from pathology department after grossing. Tissues were fixed in $10 \%$ formalin and dehydrated in ascending order of alcohol concentration. Tissues were kept in paraffin wax and blocks were prepared. Sections were cut and fixed on slide with the help of Mayer's solution. Double staining was done and the slides were kept on xylene and hydrated in descending alcohol concentration. The slides were stained with hematoxylin and dehydrated up to $70 \%$ alcohol. Again, the slides were stained with eosin and then dehydrated in $90 \%$ and absolute alcohol and the slides were mounted with DPX for observation under the microscope.

\subsection{Statistical analysis-}

The statistical comparisons were performed by one way variance (ANOVA) followed by Student's t-test.

\section{Results}

In randomly selected 120 oral malignancy case of different stages, 30 cases were from 30-50 years of age group and 54 patients were from 51-70 years of age group and 36 patients, and were from 71-80 years of 
age group. $53.33 \%$ of total patients belonged to grade I oral malignancy and the least number of patients (12.5\%) fell under grade II. Almost $20.83 \%$ of total patients suffered from grade III.

Table 1: Age and stage wise distribution of oral malignancy cases

\begin{tabular}{|l|l|l|l|l|}
\hline \multirow{2}{*}{ Age groups } & \multicolumn{3}{|c|}{ Oral malignant cases } & Total \\
\cline { 2 - 5 } & I & II & III & \\
\hline $30-50$ years & 9 & 14 & 7 & 30 \\
\hline $51-70$ years & 43 & 8 & 21 & 78 \\
\hline $71-80$ years & & - & - & 12 \\
\hline Total & 12 & 22 & 28 & 120 \\
\hline Percentage & 64 & $12.5 \%$ & $20.83 \%$ & $100 \%$ \\
\hline
\end{tabular}

\subsection{RBC Variation:}

Hematological studies of oral malignancy patients displayed the following pattern of variation. As per text figure 1 , mean \pm S.D of RBC count was $5.15 \pm 0.75$ for normal controls; $4.11 \pm .55$ in patients with grade I; $4.3 \pm .375$ in patients with grade II and $4.1 \pm .52\left(\mathrm{X}^{6} 0^{6} / \mu \mathrm{l}\right)$ in oral cancer patients of grade III.

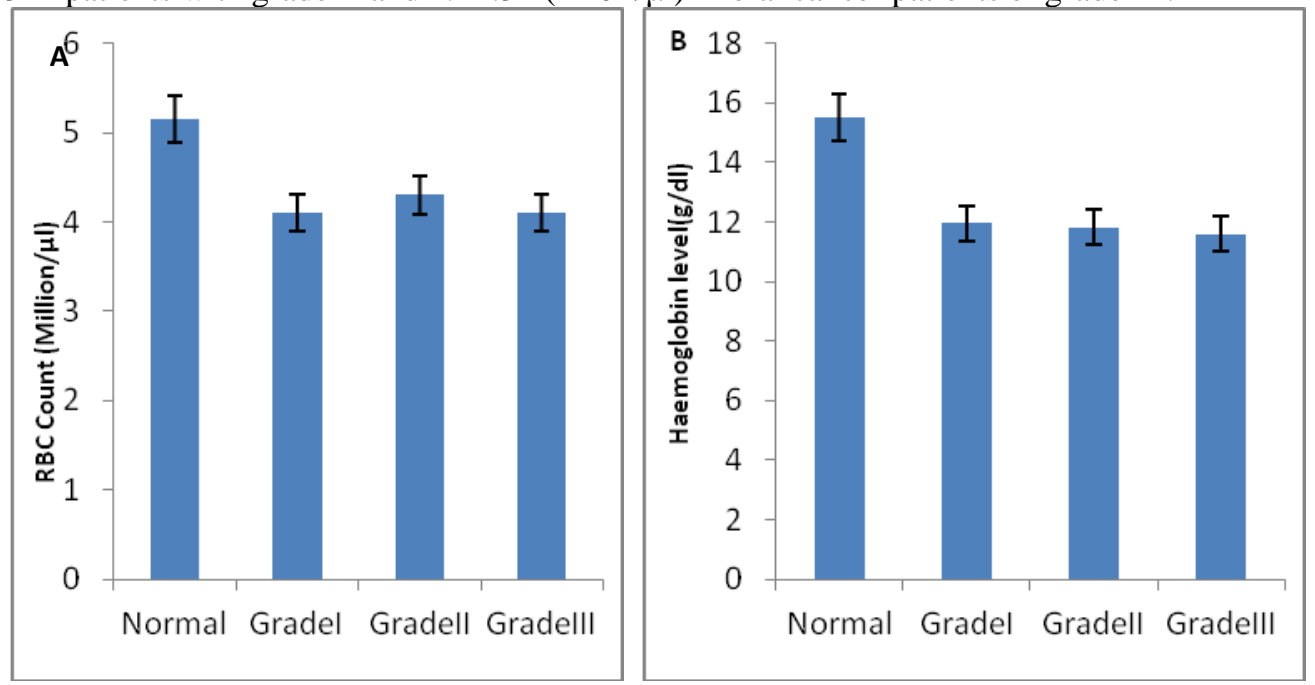

Text Fig.1- (A) RBC count in normal persons and in different grades of patients with oral cancer. (B) Hemoglobin levels in normal persons and different grades of oral cancer patients.

\subsection{Hemoglobin variation:}

Hemoglobin levels in normal persons and in different grades of oral cancer showed an inconsequential pattern. Text Fig.1B shows almost static graph when hemoglobin levels of different grades of oral cancer were calculated and it revealed insignificant correlation. Mean \pm S.D of hemoglobin count of normal persons was $15.5 \pm 0.5$ while it was nearly similar at $11.96 \pm 1.78,11.83 \pm 1.96$ and $11.6 \pm .50\left(\mathrm{X} 10^{6} / \mu \mathrm{l}\right)$, respectively for patients with grade I, II and III.

\subsection{WBC variation:}

WBC count was done and as text fig 2 demonstrates, mean \pm S.D of WBC count of normal persons was $7.15 \pm 3.5$, while it was $11.30 \pm 5.09,11.5 \pm 2.487$ and $10.5 \pm 2.37\left(\mathrm{X} 10^{6} / \mu \mathrm{l}\right)$ in grades I, II and III respectively in patients of OSCC. 

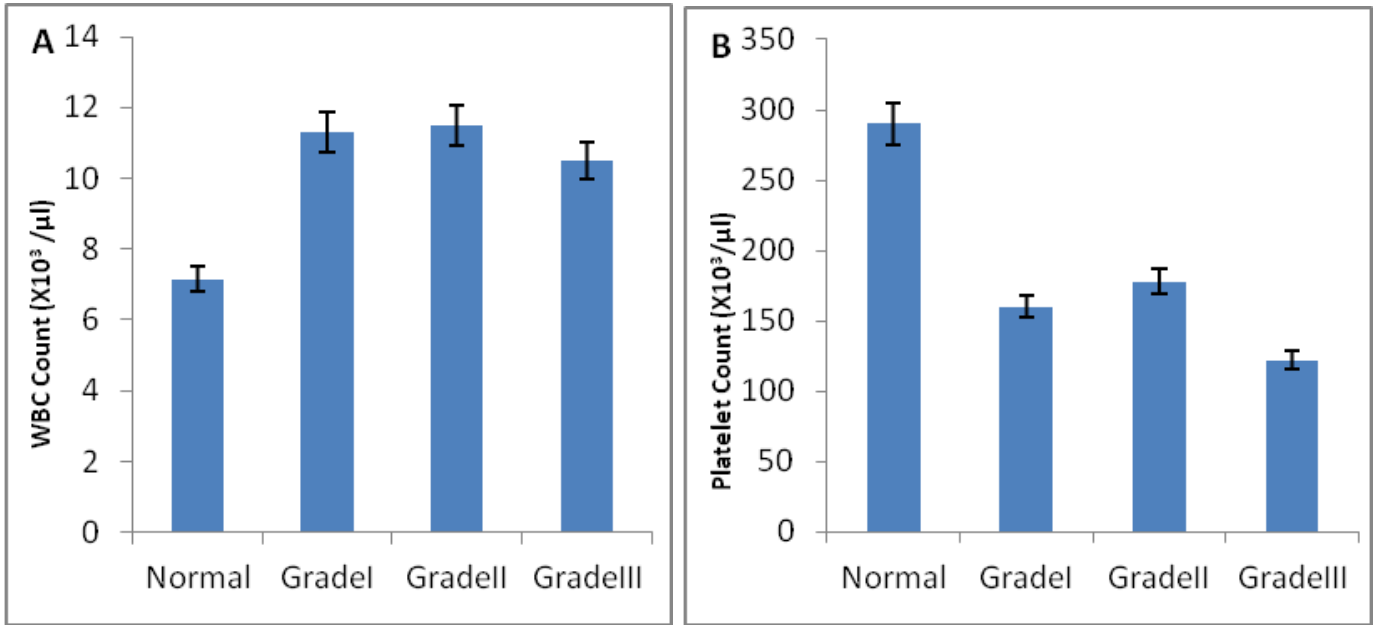

Text Fig. 2- (A) WBC count of normal persons and patients with oral cancer of different grades (B) Platelet counts in blood of normal persons and different grades of patients with oral cancer.

\subsection{Platelet variation:}

Platelets, on the other hand, manifests a different pattern as can be seen text fig. 2, according to which mean \pm S.D values of platelet count of normal persons was $290 \pm 150$, while grade I OSCC patients had $160.25 \pm 73.60$, grade II had a comparatively higher platelet count of $177.66 \pm 76.35$ but the least count was observed in the blood samples of oral cancer patients of grade III which was only $122.2 \pm 24.88\left(\mathrm{X}^{6} 0^{6} / \mu \mathrm{l}\right)$.

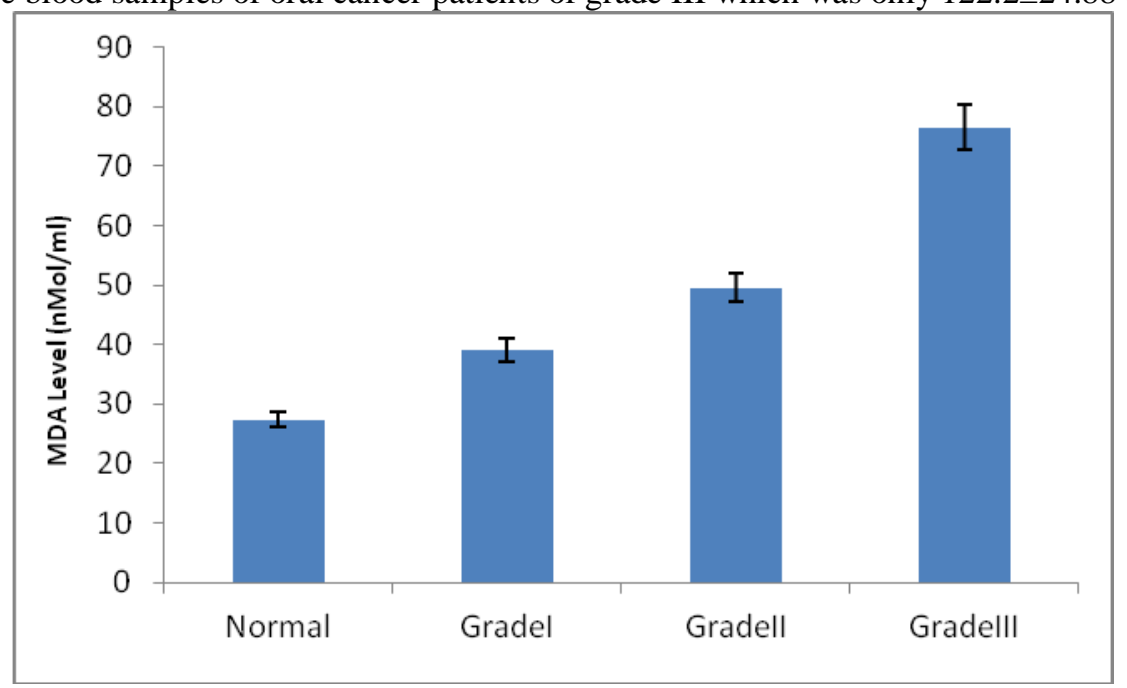

Text Fig. 3- Concentrations of MDA level in normal persons and patients with oral cancer of different grades.

\subsection{MDA level:}

When MDA levels of normal patients and oral cancer patients of different grades were scrutinized, a consistently increasing pattern was observed. Mean \pm S.D of MDA level was $27.4 \pm 3.75,39.11 \pm 9.03,49.6 \pm 6.93$ and $76.54 \pm 25.68\left(\mathrm{X} 10^{6} / \mu \mathrm{l}\right)$ in normal, grade I, grade II and grade III in patients of OSCC respectively.

\subsection{Estrogen Level}

Estrogen levels were estimated for 31 out of 120 patients of oral cancer, out of which 18 were male patients and 13 were females. (text fig. 4). A very astonishing result was procured when estrogen levels of males and females suffering from OSCC were compared. Males surprisingly showed an extremely high level of estrogen when compared to their female counterpart. Female patients of OSCC demonstrated a regular pattern of estrogen as they show in other type of cancer. 


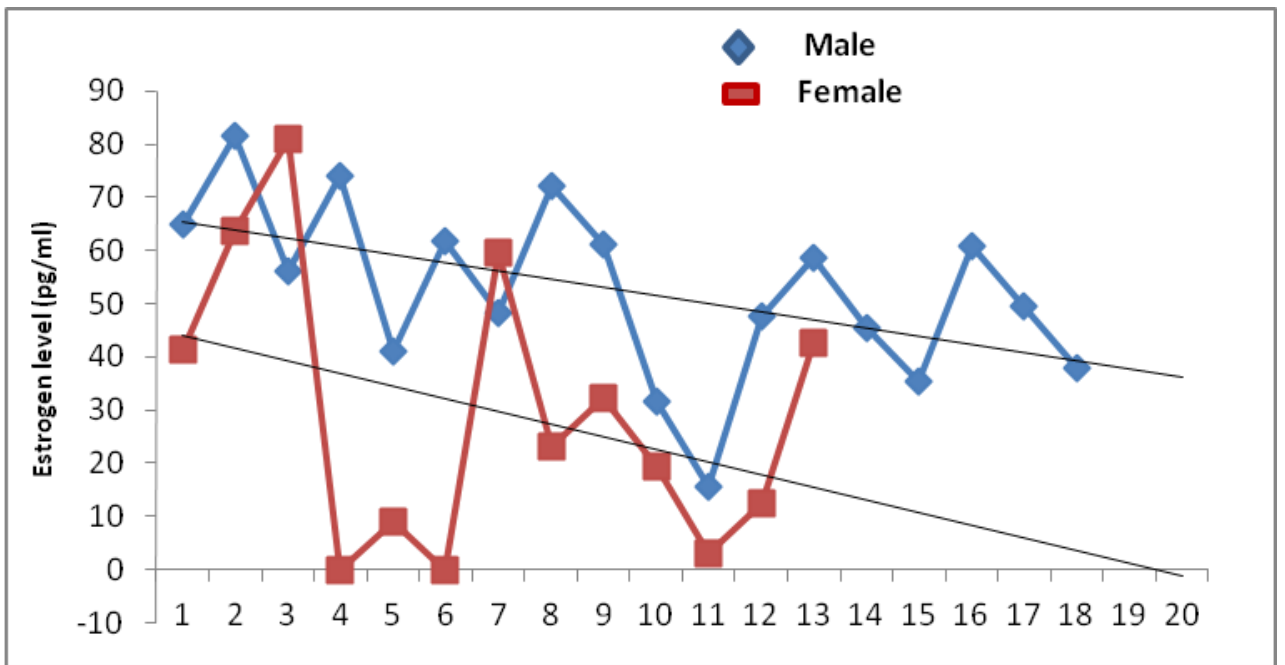

Text fig. 4- A comparative study of estrogen levels in male and female patients of OSCC.

\begin{tabular}{|l|l|l|l|l|l|}
\hline & $\begin{array}{l}\text { Healthy } \\
\text { persons }\end{array}$ & $\begin{array}{l}\text { OSCC } \\
\text { Grade I }\end{array}$ & $\begin{array}{l}\text { OSCC } \\
\text { Grade II }\end{array}$ & OSCC Gardenia & P-value \\
\hline $\begin{array}{l}\text { MDA Level } \\
(\mathrm{nMol} / \mathrm{ml})\end{array}$ & $27.433 \pm 2.617$ & $39.11 \pm 9.031$ & $49.6 \pm 6.53$ & $76.4 \pm 25.68$ & $<0.0042$ \\
\hline $\begin{array}{l}\text { RBC count } \\
(\mathrm{Million} / \mu \mathrm{l})\end{array}$ & $5.15 \pm 0.75$ & $4.11 \pm 0.55$ & $4.3 \pm 0.375$ & $4.1 \pm 0.52$ & $<0.0372$ \\
\hline $\begin{array}{l}\text { Hemoglobin } \\
\text { level }(\mathrm{g} / \mathrm{dl})\end{array}$ & $15.5 \pm 2.5$ & $11.96 \pm 1.78$ & $11.83 \pm 1.96$ & $11.6 \pm 0.5$ & $<0.0001$ \\
\hline $\begin{array}{l}\mathrm{WBC} \text { count } \\
\left(\mathrm{X} 10^{3} / \mu \mathrm{l}\right)\end{array}$ & $7.15 \pm 3.55$ & $11.30 \pm 5.09$ & $11.5 \pm 2.48$ & $10.5 \pm 2.37$ & $<0.0005$ \\
\hline $\begin{array}{l}\text { Platelet count } \\
\left(\mathrm{X} 10^{3} / \mu \mathrm{l}\right)\end{array}$ & $290 \pm 150$ & $160 \pm 73.6$ & $177.66 \pm 76.37$ & $122.2 \pm 24.88$ & $<0.0001$ \\
\hline
\end{tabular}

Table 2- elaborated mean \pm S.D of various parameters (MDA level, RBC count, WBC count, Hemoglobin level and platelet count) with their statistical significance values.

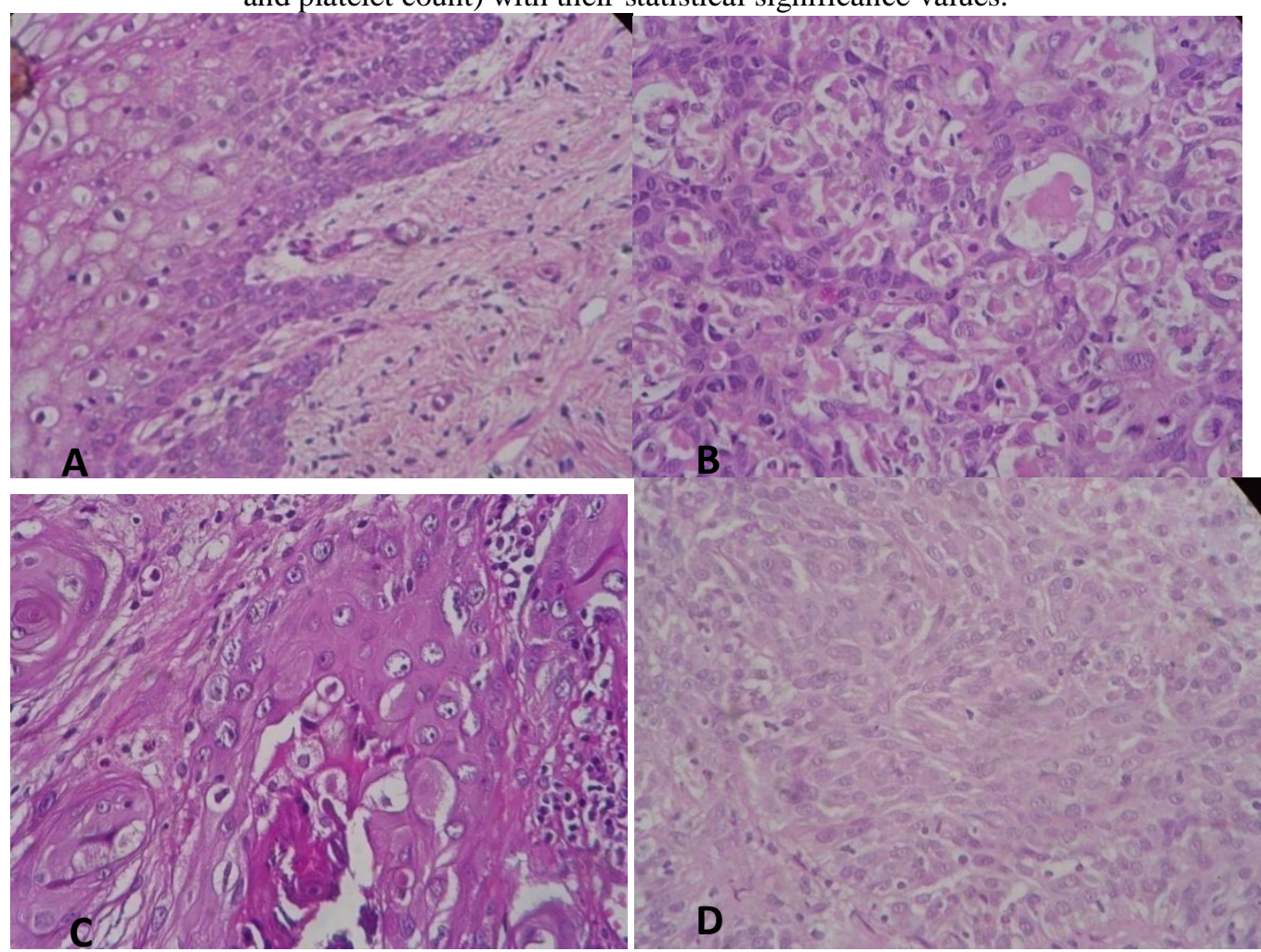

Fig. 01- Microphotographs (X40) of different grades of OSCC (A) non-cancerous tissue architecture (B) section of oral squamous cell carcinoma grade I (C) OSCC grade II and (D) OSCC grade III. 

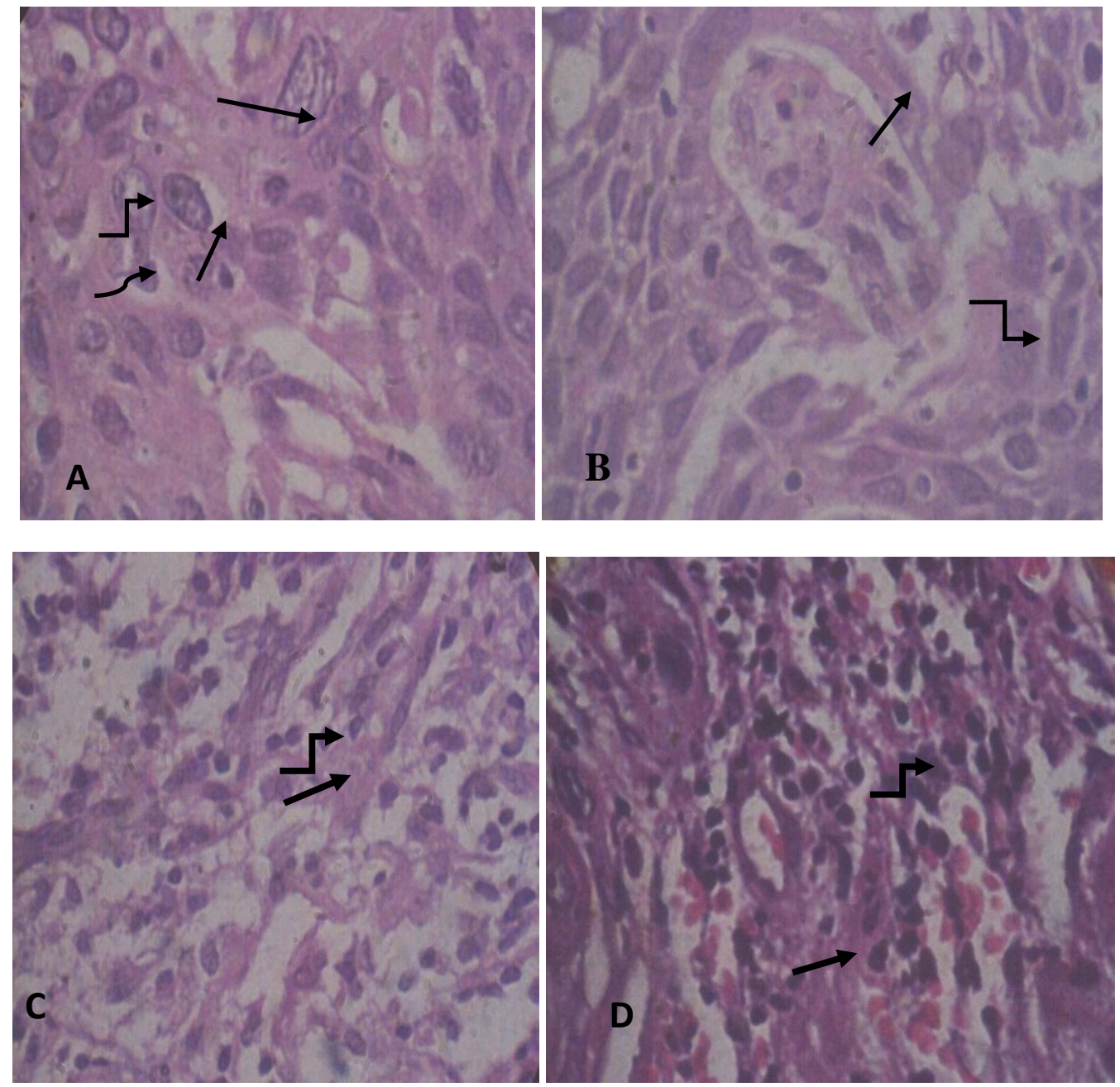

Fig. 2- Microphotographs (X100) of tissue of OSCC (A) nucleolus are clearly visible as denoted by straight arrows and separation of nuclei from cytoplasm (curved arrow connector) from enlarged nucleolus (elbow connector). (B) Blebbing of cytoplasm (straight arrow) and loss of nuclei (elbow connector), (C) nuclei effusing out (elbow connector), leaving cytoplasm empty (straight arrow), (D) cytoplasmic diffusion (straight arrow) and hyperchromatic nuclei (elbow connector).

Histopathological study of section of oral cancer tissue was performed according to a recent malignancy grading system outlined by ANNEROTH et al [22]. It is clear from fig.1A that in normal tissue, the squamous lining is hyperplastic and hyperkeratotic with acanthosis and elongated retepegs infiltrating stroma. There is no nuclear pleomorphism. (pseudo-epitheliomatous hyperplasia)

However, when observed intently, fig. 1B disclosed more about cellular and nuclear anatomy, thus, describing its morphologic parameter. Cells in the section exhibit higher degree of keratinization $(>50 \%$ of the cells). On the other hand, little polymorphism of nuclei can be pointed with $>75 \%$ of tumor area and mitotic count was found to be 1HPF (high power field). On the basis of such observations, the section was defined as grade I. Moreover, malignancy of grade I was further characterized by its pattern of invasion which was seen to be pushing and delineated with infiltrating borders as well as lympho-plasmacytic infiltration was observed in stroma.

While categorizing on the basis of similar pattern of grading in fig. 1C, it was marked with moderately keratinized (5-20\%) cells, more nuclear polymorphism in (50-75\%) mature cells and number of mitoses was 2 HPF. Solid core bands was seen to be infiltrating and only lamina propia was involved in invasion. Hence, fig 1 $\mathrm{C}$ was defined it to be grade II.

Number of cords $(>15)$ of cells invading the adjoining structure were seen. As low as $5-20 \%$ of the cells were found to be keratinized. Abundant nuclear polymorphism (25-50\% mature cells) was characterized and mitotic count was 4 , which defines the fig. $1 \mathrm{D}$ as grade III.

\section{Discussion}

It is not possible to outline a definite factor responsible for the development of cancer; however, certain etiologies are characteristically associated with oral cancer. Epstein - Barr virus, chewing and smoking of 
tobacco and consumption of alcohol are primary etiological agents linked to oral cancer. Oxidative stress is markedly elevated due to large production of ROS which attacks the lipid to generate MDA as a by-product and MDA causes significant alteration in the structural integrity and function of cell membrane [11]. MDA-DNA adducts have the potential to react with cellular DNA bases $\mathrm{dG}, \mathrm{dA}$ and $\mathrm{dC}$ as revealed in studied on liver, pancreas, breast tissue and WBC [12]. The MDA level present in blood signifies the capacity of the body to handle oxidative stress [13]. As can be observed in text fig. 3, MDA levels in blood serum of OSCC patients' increases progressively with increasing grades. It implies that patients of grade III face highest oxidative stress amongst the different grades of OSCC patients. Similar results of TBARS levels have been documented in the case of oral leukoplakia [14]. Higher MDA levels in OSCC cases reflects an increased generation of free radicals and a diminished power of antioxidants to mitigate the oxidative stress in them. Raised ROS and MDA are associated with an increased carcinogenesis and increased toxicity and both these factors are related to the progression of squamous cell transformation from benign to malignant in the long run.

Red blood cells are derived from committed erythropoietic stem cells that differentiate through various stages. Nephron senses hypoxia, and in response, kidney increases erythropoietin production. Anaemia in cancer can be treated with re-oxygenation or erythropoietin doses which are linked with improved survival in patients with various malignancies [15,16,17\&18]. RBC count and hemoglobin levels in different grades of oral squamous cell carcinoma (text fig 1 A\&B) are compared with normal which shows cancer related anemia.

Leukocytes are cells for defending body from foreign particles which include Neutrophils, eosinophils, basophils, lymphocytes and monocytes. WBC count in OSCC deviates from the normal range. As per text fig. 3, the WBC count is higher in grade I and II as compared to normal controls. WBC count might have increased due to the production of tumor antigens which have been identified on tumor cells- tumor specific transplantation antigens (TSTAS) and Tumor associated transplantation antigens (TATA). Tumor specific antigens are unique to tumor cells and do not occur on normal cells in the body. They may result due to mutations in tumor cells that generate altered cellular proteins [19].

Platelets are one of the 3 cellular components of the blood, which have a very important role in the clotting of blood [20]. Platelets lack nucleus and are formed by the detachment of parts of cytoplasm of megakaryotes [21] of the bone marrow before entering circulatory blood. Cancerous patients are characterized by thrombocytopenia (low platelets) as revealed by the text figure 3B. Interestingly platelet count depicts a pattern similar to the one shown by WBC count (text fig. 2A \& B) in different grades. Although no significant correlation could be possibly established between OSCC and the examined LPO levels or the hematological parameters like the level of RBC count, Hemoglobin level, WBC count and platelet count but the variation from healthy controls was marked.

Estrogen has been established to be one of the major causative agents in the development of cancer in female reproductive organs. As per results shown by this study, estrogen levels in men with OSCC are significantly raised and they are observed to be higher than that of female counterparts. As mentioned above, aromatase activity increases in older men and probably it is involved in the process due to which more testosterone is converted to estrogen.

As discussed previously, lipid peroxidation results in weakening of plasma membrane and other orgenellar membrane due to degradation of PUFA to MDA. Irregular shapes are exhibited by cytoplasm as plasma membrane is almost sabotaged (fig. 2 D). Nuclei are seen to be garbled and running away from cytoplasmic premises (fig. 2C). Empty cytoplasm is predominant all over the area (fig. 2B). Nucleolus is prominent in fig. 2A and at some places, nuclei are lost or effused out. Such architectural changes in cells are caused by lipid peroxidation and its by-products which damage membrane, due to which nuclear membrane are not able to retain the integrity of the nucleus. Moreover, gradual and significant increase in MDA level from grade I to III has been shown to be inversely proportional to antioxidant enzymes but more scientific exploration in this direction might give us clues about changes in oxidative stress.

\section{Conclusion}

Elevated levels of MDA in oral squamous cell carcinoma patients are harmful for normal cellular architecture. Higher level of estrogens has been observed in males than in females diagnosed with oral cancer. This demands further investigations to understand the mechanism of oxidative stress with high MDA and high levels of estrogen which synergistically augment neoplasm progression. No concrete correlation could be established between haematological parameters and MDA levels in OSCC patients although histopathological studies affirmed the effect of oxidative stress in altering the cyto-architecture of the malignant cells.

\section{Acknowledgement}

We are grateful to Ministry of Science and Technology, DST (LSR), Government of India for providing financial support for this work. We are thankful to clinicians and staff of Mahavir Cancer Institute and 
Research Centre for their help for successful completion of the research work. We are also thankful to all patients and their attendant who volunteer and gave their blood for research work.

\section{Reference}

[1] Riess, M. L., Canara, A. K. S., Kevin, L. G., An, J. and Stowe, D. F. (2004). Reduced reactive $\mathrm{O}_{2}$ species formation and preserved mitochondrial NADH and $\left[\mathrm{ca}^{2+}\right]$ leaving during short-term $17^{\circ} \mathrm{c}$ ischemia in intact heart, Cardiovascular Research, 61(3), 580-590.

[2] Weisigen, R. A. and Fridovich, I. (1973). Superoxide dismutase. Organelle Specification, Journal of Biological Chemistry, 248(10), 3582-3592.

[3] Salganik, R.I. (2001). The benefits and hazards of antioxidants: controlling apoptosis and other protective mechanisms in cancer patients and the human population, J Am Coll Nutr, 20. 473-5.

[4] Rice-Evans, C. \& Burdon, R. (1993). Free radical-lipid interactions and their pathological consequences, Prog Lipid Res 32,71-110.

[5] Barrera, Pizzimenti, S. and Dianzani, M. U. (2008). Lipid peroxidation: Control of cell proliferation, cell differentiation and cell death, Molecular Aspects of Medicine, 29(1-2), 1-8.

Dix, .T. A. and Aikens, J. (1993). Mechanisms and biological relevance of lipid peroxidation initiation, Chemical Research in Toxicology, 6(1), 2-18.

[7] Zhao, Y., Agarwal, V. R., Mendelson, C. R. and Simpson, E.R. (1996). Estrogen biosynthesis proximal to a breast tumor is stimulated by PGE2 via cyclic AMP, leading to activation of promoter II of the CYP19 (aromatase) gene. Endocrinology society, Volume 137 Issue 12. DOI: http://dx.doi.org/10.1210/endo.137.12.8940410

[8] Ronti, T., Lupattelli, G. et al. (2006). The endocrine function of adipose tissue: an update, Clinical Endocrinology,64(4): 355-365.

[9] Nelson, D. R., Kamataki, T., Waxman, D. J., Guengerich. F. P., Estabrook, R. W., Feyereisen, R., Gonzalez, F. J., Coon, M. J., Gunsalus, I. C., Gotoh,O., Okuda, K., and Nebert, D. W. (1993). The P450 superfamily: Update on new sequences, gene mapping, accession numbers, early trivial names of enzymes, and nomenclature. DNA CellBiol. 12, 1-51.

[10] Ohkawa, H., Ohishi, N. and Yagi, K. (1979). Assay for lipid peroxides in animal tissues by thiobarbituric acid reaction. Anal Biochem, 95, 351-8.

[11] Kolanjiappan, K., Manoharan, S., Kayalvizhi, M. (2002). Measurements of erythrocyte lipids, lipid peroxidation, antioxidants and osmotic fragility in cervical cancer patients, ClinChim Acta, 326, 143-9.

[12] Marnett, L.J. (1999). Lipid peroxidation - DNA damage by malondialdehyde, Mut Res Fund Mol Mech Mutagen, 424, 83-95.

[13] Chole, R.H., Patil, R.N., Basak, A., Palandurkar, K., Bhowate, R. (2010). Estimation of serum Melanodialdehyde in oral cancer and precancer and its association with healthy individuals, gender, alcohol, and tobacco abuse, J Can Res Ther, 6, 487-91.

[14] Guven, Y., Unur, M., Bektas, K., Uslu, E., Belce, A., Demirez, E. (2005). Salivary malondialdehyde levels in patients with oral leukoplakia, Tur J Med Sci, 35, 329-32.

[15] Albain, K.S., Crowley, J.J., LeBlanc, M., et al. (1991). Survival determinants in extensive-stage non-small-cell lung cancer: The Southwest Oncology Group experience, J Clin Oncol, 9:1618-1626.

[16] Bookemeyer, C., Oechsle, K., Hartmann, J.T., et al. (2002). Treatment-induced anemia and its potential clinical impact in patients receiving sequential high dose chemotherapy for metastatic testicular cancer, Br J Cancer, 87,1066-1071.

[17] Dunst, J., Kuhnt, T., Strauss, H.G., et al. (2003). Anemia in cervical cancers: Impact on survival, pattern of relapse, and association with hypoxia and angiogenesis, Int J Radiat Oncol Biol Phys, 56:778-787.

[18] Brian, L.J., Vladimir, S., Marek, P. et al. (2005). Maintaining normal hemoglobin Levels with epoetin alfa in mainly nonanemic patients with metastatic Breast cancer receiving first line chemotherapy: A survival study. J of Clin Oncol, 23, 5962-5972,

[19] Boon, T., P, Coulie, G., and Vanden Eynde, B. (1997). Tumor antigens recognized by T cells, Immunol Today, $18,267$.

[20] Wranicz, J. K., Cygankiewicz, I. et al. (2005). The relationship between sex hormones and lipid profile in men with coronary artery disease, International Journal of Cardiology, 101(1): 105-110.

[21] Machlus, K.R., Thon, J.N., Italiano, J.E. (2014). Interpreting the developmental dance of the megakaryocyte: A review of the cellular and molecular processes mediating platelet formation. British Journal of Haematology, 165 (2), 227. 